\title{
EVALUATION OF SUSTAINABLE DEVELOPMENT INDICATORS WITH FUZZY TOPSIS BASED ON SUBJECTIVE AND OBJECTIVE WEIGHTS
}

\author{
N. Z. NANG IDAYU AND A. LAZIM \\ Mathematics Department, Faculty of Science and Technology, \\ Universiti Malaysia Terengganu (UMT), 21030, Kuala Terengganu, \\ Terengganu, Malaysia. \\ idayu_zahari@yahoo.com,lazim_m@umt.edu.my
}

\begin{abstract}
Sustainable development aims at improving and maintaining the wellbeing of people and the ecology. However, this paper focuses only on the ecological aspects. The selection of the proper ecological protection determinant plays a very important role in improving the environment of Malaysia. This paper will propose a method from Wang and Lee (2009), and Yong (2006) which applies a fuzzy TOPSIS method -- based on subjective and objective weights - to make the required selection. Four alternatives will be tested which are: prevent pollution (A1), conservation (A2), well-manage (A3), and public awareness (A4). Along with these, four criteria need to be considered: water quality factor $(\mathrm{C} 1)$, land integrity factor $(\mathrm{C} 2)$, air quality factor (C3), and biodiversity factor (C4). Finally, a numerical example of ecological protection determinant selection is used to illustrate the proposed method.
\end{abstract}

\begin{abstract}
ABSTRAK: Pembangunan lestari bermatlamat memperbaiki dan mengekalkan kesejahteraan rakyat serta ekologi. Walau bagaimanapun, kertas kajian ini hanya memberi tumpuan kepada aspek-aspek ekologi. Pemilihan penentu perlindungan serta keselamatan bagi aspek ekologi memainkan peranan yang amat penting dalam meningkatkan kualiti alam sekitar di Malaysia. Kertas kajian ini telah menggunakan kaedah Wang dan Lee (2009) dan Yong (2006) yang mengaplikasikan kaedah TOPSIS kabur berdasarkan pemberat subjektif dan objektif. Terdapat empat alternatif yang akan diuji iaitu: pencegahan pencemaran $\left(A_{1}\right)$, pemuliharaan $\left(A_{2}\right)$, pengurusan yang baik $\left(A_{3}\right)$, kesedaran orang awam $\left(\mathrm{A}_{4}\right)$. Selain itu, terdapat empat kriteria yang perlu dipertimbangkan: faktor kualiti air $\left(\mathrm{C}_{1}\right)$, faktor kualiti tanah $\left(\mathrm{C}_{2}\right)$, faktor kualiti udara $\left(\mathrm{C}_{3}\right)$, faktor kepelbagaian biologi $(\mathrm{C} 4)$. Kesimpulannya, contoh pengiraan untuk memperoleh penentu pemilihan perlindungan ekologi telah digunakan bagi menunjukkan kaedah yang dicadangkan.
\end{abstract}

KEYWORDS: sustainable development; ecological factors; subjective and objective weight; fuzzy TOPSIS

\section{INTRODUCTION}

The concept of sustainable development is a challenge of growing combination between a range of environmental issues and human being issues. Environmental and human development problems have multiplied and changed day after day [1]. The issues of sustainable development have been discussed about 70 decades ago among experts and researchers and their objectives still remain the same until today. The important objectives which always been considered including: restart growth; changing the quality of growth; 
meeting essential needs for jobs, food, energy, water and cleanliness; ensuring a sustainable level of population; and merging environment and economics in decision making [2]. There are many definition of sustainable development were used but the most accepted definition is that from the World Commission of Economic Development [3]. It is known as Bruntland Commission which refers the sustainable development as "development that meets the needs of the present without compromising the ability of future generations to meet their own needs".

Sustainable development is a difficult concept to define using mathematical terms. Experts and decision makers were proposed many methods such as human development index, ecological footprint, and time series analysis to measure and evaluate sustainable development. One of method that can be used to evaluate sustainable development is fuzzy TOPSIS (Technique for Order Performance by Similarity to Ideal Solution) based on subjective and objective weights. Fuzzy TOPSIS is one of a famous method in multiple criteria decision making (MCDM). MCDM refers to solving problems in which the data are imprecise and fuzzy. According to Chen \& Hwang, in fuzzy MCDM, ratings and weights presentation are always performed by fuzzy number $[4,5]$.

The main advantage using MCDM method is its ability to consider a large number of sustainable development attributes. Fundamentally, there are two techniques of weighting methods, subjective and objective weights. Subjective weights refer to the consideration of expert evaluation while objective weights obtain by solving mathematical models without considering decision makers preferences. The objective of this paper is to evaluate and ranking weights of sustainable development indicators with fuzzy TOPSIS approach based on subjective and objective weights. The rest of this paper is organized as follows: in Section 2, we briefly review about basic definition of fuzzy TOPSIS and related works of fuzzy TOPSIS. In Section 3, we briefly review about fuzzy TOPSIS based on subjective/ objective weights approaches. In Section 4, we illustrate the proposed approach with numerical examples. In the final section some conclusions are drawn.

\section{PRELIMINARIES}

In this section, a review of basic definition of fuzzy TOPSIS, subjective and objective weights approaches as well as related works of fuzzy TOPSIS are presented prior defining sustainable development.

Definition 1: Let a set $X$ be non-empty and finite. $A$ fuzzy set $A$ on $X$ is an expression given by [6]:

$$
A=\left\{<x, \mu_{A}(x), \gamma_{A}(x)>\mid x \in X\right\}
$$

where: $\mu_{A} X \rightarrow[0,1]$ is the membership function of the fuzzy set $A ; \mu_{A}(x) \in[0,1]$ is the membership of $x \in X$ in $A$.

Definition 2: A triangular fuzzy numbers $\widetilde{M}$ can be defined by a triple $(a, b, c)$ as shown below: 


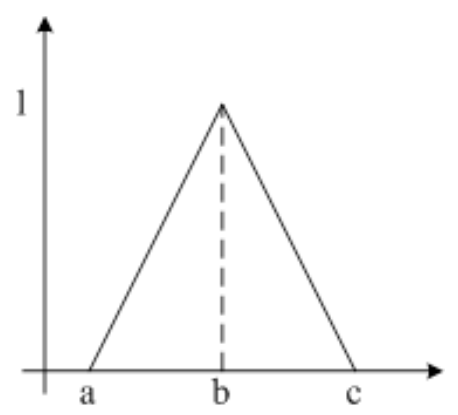

Fig.1 A triangular fuzzy number $\widetilde{M}$

$$
\mu \widetilde{M}(x)=\left\{\begin{array}{cc}
0, & x<a \\
\frac{x-a}{b-a}, & a \leq x \leq b \\
\frac{c-x}{c-b}, & b \leq x \leq c \\
0, & x>c
\end{array}\right.
$$

Definition 3: The graded mean integration representation of triangular fuzzy number $\widetilde{M}=(a 1, a 2, a 3)$ is defined as:

$$
P(\widetilde{M})=\frac{1}{6}\left(a_{1}+4 x a_{2}+a_{3}\right)
$$

Let $\widetilde{M}=\left(a_{1}, a_{2}, a_{3}\right)$ and $\left.\widetilde{Q}=b_{1}, b_{2}, b_{3}\right)$ be two triangular fuzzy numbers. So, the graded mean integration representation from both $\widetilde{M}$ and $\tilde{Q}$ can be obtained as follows:

$$
\begin{aligned}
& P(\tilde{M})=\frac{1}{6}\left(a_{1}+4 x a_{2}+a_{3}\right) \\
& P(\tilde{Q})=\frac{1}{6}\left(b_{1}+4 x b_{2}+b_{3}\right)
\end{aligned}
$$

\subsection{Related Work of Fuzzy TOPSIS}

There are a variety of criteria techniques within multiple criteria decision making (MCDM) method. MCDM method which is famous among experts and researchers are the total sum (TS), the simple additive weighting (SAW) method, the AHP, the data development analysis (DEA), the outranking approaches ELECTRE and PROMETHEE, and the TOPSIS method [7]. The concept of this method is based on the chosen alternative with the shortest distance from the positive- ideal solution (or the best possible alternative) and the longest distance from the negative- ideal solution (or the worst possible alternative). The benefits of this concept include; (a) its intuitively appealing logic, (b) its simplicity and directness, (c) its computational efficiency, and (d) its ability to measure the relative performance of the alternatives with respect to individual or all evaluation criteria in a simple mathematical form.

The vector normalization which is the method chooses the alternative with the largest value of $C_{j}^{*}$ were given in Eq. (4). 


$$
C_{j}^{*}=\frac{\sqrt{\sum_{j=1}^{n}\left(w_{j} \frac{x_{i j}}{\sqrt{\sum_{i=1}^{m} x_{i j}^{2}}}-v_{j}^{-}\right)^{2}}}{\sqrt{\sum_{j=1}^{n}\left(w_{j} \frac{x_{i j}}{\sqrt{\sum_{i=1}^{m} x_{i j}^{2}}}-v_{j}^{*}\right)^{2}}+\sqrt{\sum_{j=1}^{n}\left(w_{j} \frac{x_{i j}}{\sqrt{\sum_{i=1}^{m} x_{i j}^{2}}}-v_{j}^{-}\right)^{2}}}
$$

or it chooses the alternative with the least value of $C_{j}^{-}$formulated as in Eq. (5).

$$
C_{j}^{-}=\frac{\sqrt{\sum_{j=1}^{n}\left(w_{j} \frac{x_{i j}}{\sqrt{\sum_{i=1}^{m} x_{i j}^{2}}}-v_{j}^{*}\right)^{2}}}{\sqrt{\sum_{j=1}^{n}\left(w_{j} \frac{x_{i j}}{\sqrt{\sum_{i=1}^{m} x_{i j}^{2}}}-v_{j}^{*}\right)^{2}}+\sqrt{\sum_{j=1}^{n}\left(w_{j} \frac{x_{i j}}{\sqrt{\sum_{i=1}^{m} x_{i j}^{2}}}-v_{j}^{-}\right)^{2}}}
$$

where $i(i=1, \ldots, m)$ and $j(j=1, \ldots, n)$ are index numbers for the alternative and attributes

$w_{j}=$ the weight of the jth attribute

$x_{i j}=$ the attribute rating for ith alternative's $j$ th attribute

$v_{j}^{*}=$ the positive - ideal value for jth attribute

$v_{j}^{-}=$the negative - ideal value for the ith attribute

There are few studies that have been carried out by researchers in developing fuzzy TOPSIS method. Chen and Hwang [4,5] found a new technique of TOPSIS by transforming Hwang and Yoon's [7] method into a fuzzy case. Triantaphyllou and Lin developed TOPSIS method into a fuzzy version based on fuzzy arithmetic operation that leads to a fuzzy relative closeness for each alternative [8]. This new version offers a fuzzy relative closeness for each alternative which the closeness is badly imprecise and overstressed because of the reason of fuzzy arithmetic operations. Besides, Abo-Sinha and Abou-El-Enien [9] used TOPSIS by expanding this method for solving large- scale multiple objective programming problems involving fuzzy parameters. Chen [10] proposed the rate of each alternative as well as the weight of each criterion using linguistic terms; can be expressed in triangular fuzzy numbers. After that, he suggested to calculate the distance between two triangular fuzzy numbers using a vertex method for TOPSIS.

\section{FUZZY TOPSIS APPROACH WITH SUBJECTIVE AND OBJECTIVE WEIGHT}

\subsection{Determination of Subjective Weight}

A judgment tasks mostly requires a decision maker to integrate information from several sources to arrive at a single judgment about certain criterion. Therefore, to acquire a satisfying decision making result, the decision-maker need to construct different expert opinion. The subjective weight method is determined based on expert's evaluation. The overall evaluation of each decision maker is calculated. It will be applying in some mathematic methods such as eigenvector method, mathematical programming models and weighted least squares method. 


\subsection{Determination of Objective Weight}

The objective weight methods are determined by solving mathematical models automatically without any consideration of the decision maker's preferences. There are two techniques of objective method could be apply including a modified weighted least square method [11] and entropy. According to Deng et al., objective weighting approaches is particularly applicable for situations where reliable subjective weights cannot be obtained [12]. The entropy method is based on information theory. There is such attribute does not help in differentiating alternatives where a small weight is assigned to an attribute if it has similar attribute value across alternatives. For this paper, the Shannon entropy will be applied for objective weights approach. It is a measure of uncertainty in information formulated in terms of probability theory. We extend Shannon's concept to use entropy measure as weighting calculation method.

Definition 4: The entropy $H(X)$ of a discrete random variable $X$ is defined [13] as,

$$
\begin{aligned}
& H(X)=-\sum_{j=0}^{N-1} p\left(x_{i j}\right) \log _{2} p\left(x_{i j}\right) \\
& H(X)=-\sum_{j=0}^{N-1} p_{i j} \log _{2} p_{i j}
\end{aligned}
$$

In this paper, we recommended a method from Wang and Lee [11] and Yong [8] that proposed a fuzzy TOPSIS approach integrates subjective and objective weights to calculate the weight of each sustainable development indicators. This approach will give benefit to the decision makers' expertise and entail end- users into a whole decision making process.

The steps of fuzzy TOPSIS algorithm can be expressed as follows:

\section{Step 1: Construct a decision matrix}

Assume there $m$ alternatives $A_{i}(i=1,2, \ldots, m)$ to be evaluated against $n$ selection criteria $C_{i}(i=1,2, \ldots, n)$. Subjective assessments are to be made by decision makers (DM) to determine:

(a) the weighting vector $W=(w 1, w 2, \ldots, w j, \ldots, w n)$, and;

(b) the decision matrix $X=\left\{x_{i j}, i=1,2, \ldots, m ; j=1,2, \ldots, n\right\}$, using the linguistic terms given in Table 1.

The weighting vector $\mathrm{W}$ represents the relative importance of $\mathrm{n}$ selection criteria $C_{j}(j=1,2, \ldots, n)$ for the problem. The decision matrix $X=\left\{x_{i j}, i=1,2, \ldots, m ; j=\right.$ $1,2, \ldots, n$ represents the utility ratings of alternative $A_{i}$ with respect to selection criteria $C_{j}$. Given the weighting vector $\mathrm{W}$ and decision matrix $X$, the objective of the problem is to rank the entire alternative by giving each of them an overall utility with respect to a selection criteria. The decision matrix can be expressed as follows:

$$
\left.D=\begin{array}{c}
C_{1} \\
A_{1} \\
A_{2} \\
\vdots \\
A_{m}
\end{array} \quad \begin{array}{cccc}
x_{11} & x_{2} & \ldots & C_{n} \\
x_{21} & x_{22} & \ldots & x_{1 n} \\
\vdots & \vdots & \ddots & \vdots \\
x_{m 1} & x_{m 2} & \ldots & x_{m n}
\end{array}\right)
$$




$$
W=\left[w_{1}, w_{2}, \ldots w_{n}\right]
$$

Step 2: Both subjective and entropy- based objective weighting methods were used.

(a) Subjective: Determine the DM's weight for each criterion,

$$
\widetilde{W}=\frac{1}{n}\left(\sum_{j=1}^{n} w_{j}^{e}\right), j=1,2, \ldots, n
$$

(b) Objective: Objective weights determined using entropy measure. The decision matrix needs to be normalized for each criterion $C_{j}(j=1,2, \ldots, n)$ to gain the projection value of each criterion: $P_{i j}$.

$$
P_{i j}=\frac{x_{i j}}{\sum_{i=1}^{m} x_{i j}}
$$

After normalized the decision matrix, the entropy value, $\mathrm{e}_{\mathrm{j}}$ calculated as,

$$
e_{j}=-k \sum_{j=1 P_{i j}}^{n} \ln P_{i j}
$$

$k$ is a constant, let $k=(\ln (m))^{-1}$ The degree of divergence $\mathrm{d}_{\mathrm{i}}$ of the basic information of each criterion $C_{j}(j=1,2, \ldots, n)$ calculated as

$$
d_{j}=1-e_{j}
$$

The value $d_{j}$ represents the inherent contrast intensity of $C_{j}$. The higher the $d_{j}$ is, the more important the criterion $C_{j}$ is for the problem. The objective weight for each criterion can be obtained

$$
W_{j}=\frac{d_{j}}{\sum_{k=1}^{n} d_{k}}
$$

Step 3: The aggregate weights for each criterion $\mathrm{W}_{\mathrm{j}}$ calculated as follow:

$$
\tilde{X}_{i j}=\frac{1}{n}\left(\sum_{e=1}^{n} \tilde{x}_{i j}^{e}\right), i=1,2, \ldots, m
$$

Step 4: The decision matrix is obtained to identify the $j$ th criteria with respect to $i$ th alternative

$$
\tilde{R}=\left[\tilde{r}_{i j}\right]_{m x k}, R_{i j}=\widetilde{W}_{j} \otimes \tilde{X}_{i j}
$$

Step 5: Normalize the decision matrix in order to make each criterion value is limited between 0 and 1 , so that each criterion is comparable. The initial data with respect to each criterion will be normalized by dividing the sum of criterion value. For fuzzy data denoted by triangular fuzzy number as $\left(a_{i j}, b_{i j}, c_{i j}\right)$, the normalized values are calculated as follows:

$$
\begin{aligned}
& \tilde{r}_{i j}=\left\{\left(\frac{a_{i j}}{c_{i j}^{+}}, \frac{b_{i j}}{c_{i j}^{+}}, \frac{c_{i j}}{c_{i j}^{+}}\right)\right\}, j \in B \\
& \tilde{r}_{i j}=\left\{\left(\frac{a_{i j}}{c_{i j}^{-}}, \frac{b_{i j}}{c_{i j}^{-}}, \frac{c_{i j}}{c_{i j}^{-}}\right)\right\}, j \in C
\end{aligned}
$$




$$
\begin{aligned}
& c_{j}^{+}=\max _{i} c_{i j} \text { if } j \in B \\
& a_{j}^{+}=\max _{i} a_{i j} \text { if } j \in C
\end{aligned}
$$

Step 6: The overall performance evaluation for each alternative is calculated by multiplying the aggregate weights for each normalized criterion.

$$
\tilde{V}=\left(\tilde{v}_{i j}\right)_{m x k}, i=1,2, \ldots, m ; j=1,2, \ldots, n
$$

Where,

$$
v_{i j}=\frac{v_{i j}}{\sqrt{\sum_{i=1}^{m}\left(v_{i j}\right)^{2}}}
$$

Step 7: The positive ideal solution $A^{+}$and negative ideal solution $A^{-}$are determined. The weighted normalized values for each criterion are sorted in descending order.

$$
\begin{aligned}
& A^{+}=\left(\tilde{v}_{1}^{+}, \tilde{v}_{2}^{+}, \ldots, \tilde{v}_{k}^{+}\right) \\
& A^{-}=\left(\tilde{v}_{1}^{-}, \tilde{v}_{2}^{-}, \ldots, \tilde{v}_{k}^{-}\right)
\end{aligned}
$$

Step 8: The distance from the positive ideal solution and the negative ideal solution are calculated for each alternative. According to Bojadziev and Bojadziev (1995), the distance between two triangular fuzzy numbers $A_{1}=\left(a_{1}, b_{1}, c_{1}\right)$ and $A_{2}=\left(a_{2}, b_{2}, c_{2}\right)$ is calculated as

$$
\begin{aligned}
& d\left(A_{1}, A_{2}\right)=\sqrt{\frac{1}{3}\left[\left(a_{1}-a_{2}\right)^{2}+\left(b_{1}-b_{2}\right)^{2}+\left(c_{1}-c_{2}\right)^{2}\right]} \\
& d_{i}^{+}=\sqrt{\sum_{j=1}^{n}\left(\tilde{v}_{i j}-\tilde{v}_{j}^{+}\right)^{2}}, i=1,2, \ldots, m \\
& d_{i}^{-}=\sqrt{\sum_{j=1}^{n}\left(\tilde{v}_{i j}-\tilde{v}_{j}^{-}\right)^{2}}, i=1,2, \ldots, m
\end{aligned}
$$

Step 9: The closeness coefficient (CC) is calculated. Rank each CC of each alternative in descending order. The alternative with higher $\mathrm{CC}$ value will be the best choice.

$$
C C_{i}=\frac{d_{i}^{-}}{d_{i}^{+}+d_{i}^{-}}, i=1,2, \ldots, m
$$

\section{NUMERICAL EXAMPLE}

In this section, we provide a numerical example to test the ability of the proposed method from Wang and Lee [11] and Yong [14]. A selection of ecological protection determinant can be calculated as a multiple- criteria decision making problem in which alternative are the practice of ecological control measures to be selected and attributes are those criterion under consideration. A government desires to select the best alternative for the ecological protection determinant in order to improve quality of environment in Malaysia. After preliminary screening, four alternatives: prevent pollution $\left(A_{1}\right)$, conservation $\left(A_{2}\right)$, well-manage $\left(A_{3}\right)$, public awareness $\left(A_{4}\right)$ have remained in the candidate list. There are four criteria need to be considered: i) water quality factor $\left(\mathrm{C}_{1}\right)$, ii) land quality factor $\left(C_{2}\right)$, iii) air quality factor $\left(C_{3}\right)$, iv) biodiversity factor $\left(C_{4}\right)$ 


$$
\left.\begin{array}{c}
C_{1} \\
A_{1} \\
A_{2} \\
A_{3} \\
A_{4}
\end{array} \quad \begin{array}{cccc}
8 & C_{2} & C_{3} & C_{4} \\
8 & 5.5 & 32 & 17 \\
29 & 11.7 & 11 & 7 \\
15.6 & 21 & 34 & 15.9
\end{array}\right)
$$

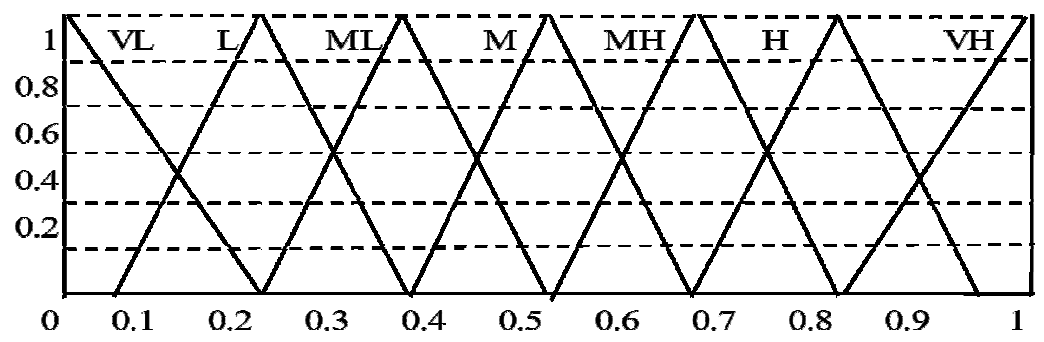

Fig. 2 The linguistic variables for each criterion.

Step 1: The linguistic variables developed by Chen and Hwang [4] are used as illustrated in Fig. 2. The triangular fuzzy number used to express importance for each criterion. The terms of "very low" to "very high" is the range of linguistic expressions.

Table 1: Fuzzy linguistic terms and correspondent fuzzy numbers for each criterion.

\begin{tabular}{cccc}
\hline Importance & Abbreviation & Fuzzy Number & $\begin{array}{c}\text { Graded mean } \\
\text { integration for the } \\
\text { importance weight } \\
\text { of the criterion }\end{array}$ \\
\hline Very Low & VL & $(0,0,0.2)$ & 0.0333 \\
Low & $\mathrm{L}$ & $(0.05,0.2,0.35)$ & 0.2000 \\
Medium Low & $\mathrm{ML}$ & $(0.2,0.35,0.5)$ & 0.3500 \\
Medium & $\mathrm{M}$ & $(0.35,0.5,0.65)$ & 0.5000 \\
Medium High & $\mathrm{MH}$ & $(0.5,0.65,0.8)$ & 0.6500 \\
High & $\mathrm{H}$ & $(0.65,0.8,0.95)$ & 0.8000 \\
Very High & $\mathrm{VH}$ & $(0.8,1,1)$ & 0.9667 \\
\hline
\end{tabular}

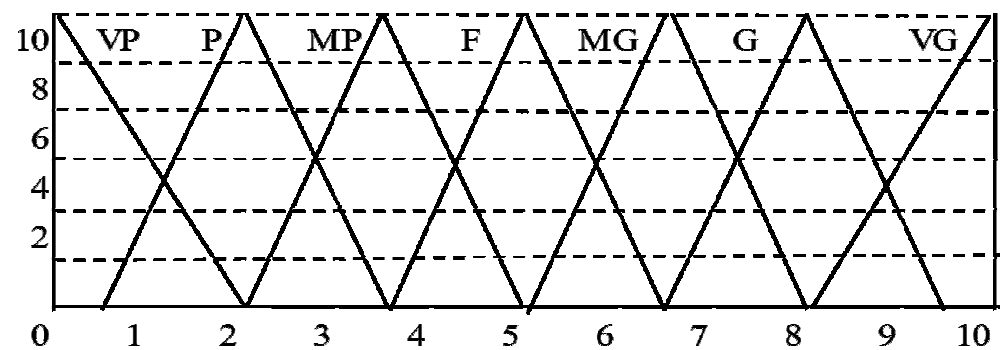

Fig. 3: The fuzzy linguistic variables for each alternative.

Step 2: Similar to the step 1, the linguistic terms and fuzzy number are decided. The linguistic terms expression is "very poor" to "very good" will be the range of its triangular fuzzy number. 
Table 2: Fuzzy linguistic terms and correspondent fuzzy number for each alternative

\begin{tabular}{cccc}
\hline Importance & Abbreviation & Fuzzy Number & $\begin{array}{c}\text { Graded mean } \\
\text { integration for the } \\
\text { ratings }\end{array}$ \\
\hline Very Poor & VP & $(0,0,2)$ & 0.3333 \\
Poor & P & $(1.5,2,3.5)$ & 2.1667 \\
Medium Poor & MP & $(2,3.5,5)$ & 3.5000 \\
Fair & F & $(3.5,5,6.5)$ & 5.0000 \\
Medium Good & MG & $(5,6.5,8)$ & 6.5000 \\
Good & G & $(6.5,8,9.5)$ & 8.0000 \\
Very Good & VG & $(8,10,10)$ & 9.6667 \\
\hline
\end{tabular}

Step 3: The criterion's weight rated by decision maker according to linguistic terms.

Table 3: The importance weights of the attributes

\begin{tabular}{ccccc}
\hline \multirow{2}{*}{ Criteria } & \multicolumn{4}{c}{ Decision Maker (DM) } \\
\cline { 2 - 5 } & $\boldsymbol{D}_{\mathbf{1}}$ & $\boldsymbol{D}_{\mathbf{2}}$ & $\boldsymbol{D}_{\mathbf{3}}$ & $\boldsymbol{D}_{\mathbf{4}}$ \\
\hline $\boldsymbol{C}_{\mathbf{1}}$ & $\mathrm{ML}$ & $\mathrm{H}$ & $\mathrm{M}$ & $\mathrm{VH}$ \\
$\boldsymbol{C}_{\mathbf{2}}$ & $\mathrm{L}$ & $\mathrm{VH}$ & $\mathrm{VH}$ & $\mathrm{VH}$ \\
$\boldsymbol{C}_{\mathbf{3}}$ & $\mathrm{MH}$ & $\mathrm{VH}$ & $\mathrm{M}$ & $\mathrm{M}$ \\
$\boldsymbol{C}_{\mathbf{4}}$ & $\mathrm{H}$ & $\mathrm{VL}$ & $\mathrm{MH}$ & $\mathrm{ML}$ \\
\hline
\end{tabular}

Step 4: Based on the assessment values in Table 3, fuzzy weights of each decision maker's attribute is computed.

Table 4: The aggregated fuzzy weights

\begin{tabular}{cc}
\hline Criteria & Average Fuzzy Number \\
\hline $\boldsymbol{C}_{\mathbf{1}}$ & $(0.5,0.66,0.74)$ \\
$\boldsymbol{C}_{\mathbf{2}}$ & $(0.1,0.8,0.84)$ \\
$\boldsymbol{C}_{\mathbf{3}}$ & $(0.5,0.66,0.76)$ \\
$\boldsymbol{C}_{\mathbf{4}}$ & $(0.34,0.45,0.61)$ \\
\hline
\end{tabular}

The decision-makers weight for each criterion shown as follows:

Table 5: The DM's weights for each criterion

\begin{tabular}{cc}
\hline Criteria & DM's weight $(\widetilde{\boldsymbol{W}})$ \\
\hline $\boldsymbol{C}_{\mathbf{1}}$ & 0.6333 \\
$\boldsymbol{C}_{\mathbf{2}}$ & 0.7500 \\
$\boldsymbol{C}_{\mathbf{3}}$ & 0.6400 \\
$\boldsymbol{C}_{\mathbf{4}}$ & 0.4333 \\
\hline
\end{tabular}


Step 5: According to Table 3, crisp projection for each criterion in Table 6 is derived.

Table 6: Each criterion projection value

\begin{tabular}{ccccc}
\hline \multirow{2}{*}{ Criteria } & \multicolumn{4}{c}{ Decision Maker (DM) } \\
\cline { 2 - 5 } & $\boldsymbol{D}_{\mathbf{1}}$ & $\boldsymbol{D}_{\mathbf{2}}$ & $\boldsymbol{D}_{\mathbf{3}}$ & $\boldsymbol{D}_{\mathbf{4}}$ \\
\hline $\boldsymbol{C}_{\mathbf{1}}$ & 0.3500 & 0.8000 & 0.5000 & 0.9300 \\
$\boldsymbol{C}_{\boldsymbol{2}}$ & 0.2000 & 0.9300 & 0.9300 & 0.9300 \\
$\boldsymbol{C}_{\boldsymbol{3}}$ & 0.6500 & 0.9300 & 0.5000 & 0.5000 \\
$\boldsymbol{C}_{\boldsymbol{4}}$ & 0.8000 & 0.0700 & 0.6500 & 0.3500 \\
\hline
\end{tabular}

Step 6: We calculate $e_{j}, d_{j}$, and $w_{j}$ according to Eq. (14) to (16) respectively. According to Table 7, it is clearly identified that $C_{2}$ is the most important criterion.

Table 7: Entropy- based weights $\left(w_{j}\right)$ for each attributes

\begin{tabular}{cccc}
\hline $\mathbf{C}$ & $\boldsymbol{e}_{\boldsymbol{j}}$ & $\boldsymbol{d}_{\boldsymbol{j}}$ & $\boldsymbol{w}_{\boldsymbol{j}}$ \\
\hline $\boldsymbol{C}_{\boldsymbol{1}}$ & 0.94366 & 0.05634 & 0.12603 \\
$\boldsymbol{C}_{\boldsymbol{2}}$ & 0.72409 & 0.27591 & 0.61722 \\
$\boldsymbol{C}_{\boldsymbol{3}}$ & 0.92050 & 0.07950 & 0.17784 \\
$\boldsymbol{C}_{\boldsymbol{4}}$ & 0.96473 & 0.03527 & 0.07890 \\
\hline
\end{tabular}

Step 7: The importance of each decision- maker described by linguistic weighting variables as shown in Table 8 . For the benefit- related criteria and cost- related criteria, the rate is calculated based on the graded mean integration representation shown as follows:

\begin{tabular}{|c|c|c|c|c|}
\hline & $C_{1}$ & $C_{2}$ & $C_{3}$ & $C_{4}$ \\
\hline$A_{1}$ & {$[5.3750$} & 6.5417 & 5.0834 & 6.1250 \\
\hline$A$ & 6.2084 & 3.5000 & 6.1250 & 4.9583 \\
\hline$A_{3}$ & 5.0834 & 3.1250 & 4.2917 & 4.6667 \\
\hline & L.0833 & 5.7500 & 6.8750 & 6.62 \\
\hline
\end{tabular}

Table 8: The Initial decision-maker rating table

\begin{tabular}{cccccccccc}
\hline \multirow{2}{*}{ Criteria } & \multirow{2}{*}{ Candidates } & \multicolumn{9}{c}{ Decision Maker } & $\boldsymbol{D}_{\mathbf{1}}$ & $\boldsymbol{D}_{\mathbf{2}}$ & $\boldsymbol{D}_{\mathbf{3}}$ & \multirow{2}{*}{$\boldsymbol{D}_{\mathbf{4}}$} \\
& & $\boldsymbol{D}_{\mathbf{1}}$ & $\boldsymbol{D}_{\mathbf{2}}$ & $\boldsymbol{D}_{\mathbf{3}}$ & $\boldsymbol{D}_{\mathbf{4}}$ & & & & \\
& $\mathrm{A}_{1}$ & $\mathrm{~F}$ & $\mathrm{~F}$ & $\mathrm{G}$ & $\mathrm{MP}$ & 5.0000 & 5.0000 & 8.0000 & 3.5000 \\
\multirow{4}{*}{$\boldsymbol{C}_{\mathbf{1}}$} & $\mathrm{A}_{2}$ & $\mathrm{G}$ & $\mathrm{F}$ & VG & P & 8.0000 & 5.0000 & 9.6667 & 2.1667 \\
& $\mathrm{~A}_{3}$ & VG & P & MP & F & 9.6667 & 2.1667 & 3.5000 & 5.0000 \\
& $\mathrm{~A}_{4}$ & MP & VP & MP & F & 3.5000 & 0.3333 & 3.5000 & 5.0000 \\
\hline \multirow{2}{*}{$\boldsymbol{C}_{\mathbf{2}}$} & $\mathrm{A}_{1}$ & G & F & VG & MP & 8.0000 & 5.0000 & 9.6667 & 3.5000 \\
& $\mathrm{~A}_{2}$ & MP & VP & P & G & 3.5000 & 0.3333 & 2.1667 & 8.0000 \\
\hline
\end{tabular}




\begin{tabular}{cccccccccc}
\hline & $\mathrm{A}_{3}$ & F & VP & P & F & 5.0000 & 0.3333 & 2.1667 & 5.0000 \\
& $\mathrm{~A}_{4}$ & F & MG & MP & G & 5.0000 & 6.5000 & 3.5000 & 8.0000 \\
\hline \multirow{6}{*}{$C_{3}$} & $\mathrm{~A}_{1}$ & F & VG & P & MP & 5.0000 & 9.6667 & 2.1667 & 3.5000 \\
& $\mathrm{~A}_{2}$ & G & F & G & MP & 8.0000 & 5.0000 & 8.0000 & 3.5000 \\
& $\mathrm{~A}_{3}$ & F & VG & P & VP & 5.0000 & 9.6667 & 2.1667 & 0.3333 \\
& $\mathrm{~A}_{4}$ & MG & G & F & G & 6.5000 & 8.0000 & 5.0000 & 8.0000 \\
\hline \multirow{6}{*}{$C_{4}$} & $\mathrm{~A}_{1}$ & F & F & MG & G & 5.0000 & 5.0000 & 6.5000 & 8.0000 \\
& $\mathrm{~A}_{2}$ & VP & G & F & MG & 0.3333 & 8.0000 & 5.0000 & 6.5000 \\
& $\mathrm{~A}_{3}$ & P & MP & G & F & 2.1667 & 3.5000 & 8.0000 & 5.0000 \\
& $\mathrm{~A}_{4}$ & VG & VG & P & F & 9.6667 & 9.6667 & 2.1667 & 5.0000 \\
\hline
\end{tabular}

Step 8: The decision matrix and the normalized decision matrix will be calculated by applying Eq. (18) to (24).

i) The decision matrix

\begin{tabular}{|c|c|c|c|c|}
\hline & $C_{1}$ & $C_{2}$ & $C_{3}$ & $C_{4}$ \\
\hline$A_{1}$ & {$[3.4040$} & 4.9063 & 3.2534 & 2.654 \\
\hline & 3.9318 & 2.6250 & 3.9200 & 2.1484 \\
\hline$A_{3}$ & 3.2193 & 2.3438 & 2.7467 & 2.0221 \\
\hline & 1.9527 & 4.3125 & 4.4000 & \\
\hline
\end{tabular}

ii) The normalized decision matrix

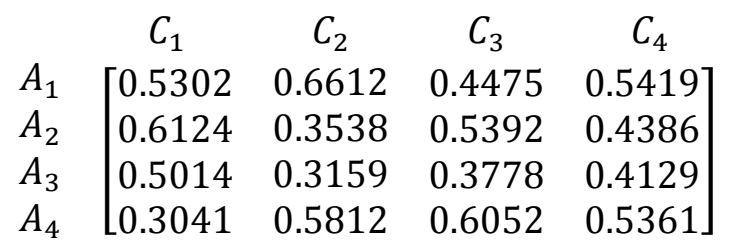

Step 9: Determined the positive- ideal solution (PIS) and negative-ideal solution (NIS) according to Eq. (7) and (8). The distance of each alternative from the positive- ideal solution (PIS) and the negative- ideal solution (NIS) is calculated respectively.

$$
\begin{aligned}
& A^{+}=\left(v_{1}^{+}, v_{2}^{+}, \ldots, v_{n}^{+}\right)=(0.6124,0.6612,0.6052,0.5861) \\
& A^{-}=\left(v_{1}^{-}, v_{2}^{-}, \ldots, v_{n}^{-}\right)=(0.3041,0.3159,0.3778,0.4129)
\end{aligned}
$$

Table 9: The distance measurement

\begin{tabular}{ccc}
\hline Alternative & $\boldsymbol{d}^{+}$ & $\boldsymbol{d}^{-}$ \\
\hline $\boldsymbol{A}_{\mathbf{1}}$ & 0.1832 & 0.4380 \\
$\boldsymbol{A}_{\mathbf{2}}$ & 0.3473 & 0.3510 \\
$\boldsymbol{A}_{\mathbf{3}}$ & 0.4618 & 0.1973 \\
$\boldsymbol{A}_{\mathbf{4}}$ & 0.3185 & 0.3900 \\
\hline
\end{tabular}


Step 10: Finally, the closeness coefficient of each alternative is calculated.

Table 10: Closeness coefficient table

\begin{tabular}{ccc}
\hline Alternative & CC & Ranking \\
\hline $\boldsymbol{A}_{\mathbf{1}}$ & 0.7051 & 1 \\
$\boldsymbol{A}_{\mathbf{2}}$ & 0.5026 & 3 \\
$\boldsymbol{A}_{\mathbf{3}}$ & 0.2993 & 4 \\
$\boldsymbol{A}_{\mathbf{4}}$ & 0.5505 & 2 \\
\hline
\end{tabular}

According to Table 10, the ranking order of four candidates is $\boldsymbol{A}_{1} \phi \boldsymbol{A}_{4} \phi \boldsymbol{A}_{2} \phi \boldsymbol{A}_{3}$. The best alternative would be $\boldsymbol{A}_{1}$ which the symbol of ' $\phi$ ' means 'is preferred to'. In this paper, the easy way to obtain fuzzy number is through applied the graded mean representation method [15]. It is very efficient and useful because it helps decreases the computation load for resulting steps of the proposed method.

\section{CONCLUSION}

The multi- criteria decision making problem will be used when there is a group of decision- makers. Among many famous MCDM methods, fuzzy TOPSIS is the best way. It is a practical technique to rank or choose the best alternative in their computation. It is an attractive way because the limited subjective input is needed from the decision- maker. The advantage of using this method is that its ability to find the best alternative promptly [16]. In this paper, the proposed method is used to calculate weight of each criterion and find the best alternative for the ecological protection determinant. In addition, the distance between positive- ideal solution and negative- ideal solution is easily determined without ranking fuzzy number because the graded mean representation method is applied.

\section{ACKNOWLEDGEMENT}

The authors thank the Ministry of Higher Education, Malaysia for financing this research (Fundamental Research Grant Scheme, No.59148).

\section{REFERENCES}

[1] J. Holmberg, and S. Karlsson, "On designing socio-ecological indicators, in Svedin, U. and Hägerhäll-Aniansson, B. (eds.)", Society and Environment: A Swedish Research Perspective, Kluwer Academic Publishers: Dordrecht, 1992.

[2] G. P. Glasby, "Concept of sustainable development: a meaningful goal", The Science of the Total Environment. Vol. 159. UK: Elsevier, 1995. 67-80.

[3] World Commission on Environment and Development (WCED), "Our Common Future", , Oxford: Oxford University Press, 1987.

[4] S. J. Chen and C. L. Hwang, "Fuzzy Multiple Attribute Decision Making Methods and Applications", Berlin : Springer - Verlag, , 1992.

[5] S. J. Chen, \& C.L Hwang, "Fuzzy Multiple Attribute Decision Making", Lecture Notes In Economics And Mathematical System Series", Vol. 375 New York: Springer-Verlag, 1992.

[6] L. A. Zadeh, "Fuzzy Sets”, Information and Control, 8 (1965): 338- 53.8 August. 2014. 
[7] C. L. Hwang, \& K. S. Yoon, "Multiple Attribute Decision Making: Methods And Applications", Berlin: Springer-Verlag, 1981.

[8] E. Triantaphyllou, and C. T. Lin, "Development And Evaluation Of Five Fuzzy Multiattribute Decision- Making Methods", International Journal of Approximate Reasoning, 14. (1996): 281-310. 8 August. 2014.

[9] M. Abo- Sinna and T. H.M Abou- El- Enien, "An Interactive Algorithm For Large Scale Multiple Objective Programming Problems With Fuzzy Parameters Through TOPSIS Approach”, Applied Mathematics and Computation, 177.2 (2005): 515-527. 8 August. 2014.

[10] T. C. Chen, "Extensions of the TOPSIS For Group Decision- Making Under Fuzzy Environment", Fuzzy Sets and Systems, 114. (2000):1-9. 8 August. 2014.

[11] T. C. Wang, and H. D. Lee, "Developing A Fuzzy TOPSIS Approach Based On Subjective Weights And Objective Weights", Expert Systems with Application. 36. (2009):8980-85. 8 August. 2014.

[12] H. Deng, C. H. Yeh, \& R. J Willis, "Inter-Company Comparison Using Modified TOPSIS With Objective Weights", Computers and Operations Research. 27. (2000):963-73. 8 August. 2014.

[13] C.E. Shannon, "A Mathematical Theory of Communication", Journal of Bell System And Technology. 27. (1948):379-423, 623-59. 8 August. 2014.

[14] D. Yong, "Plant location selection based on fuzzy TOPSIS", The International Journal of Advance Manufacturing. 28. (2006):839-44. 8 August. 2014.

[15] C. C. Chou, "The Canonical Representation of Multiplication Operation On Triangular Fuzzy Numbers", International Journal Of Applied Mathematics And Computer Science 45. (2003):1601-10. 8 August. 2014.

[16] C. Parkan, and M. L. Wu, "On The Equivalence of Operational Performance Measurement And Multiple Attribute Decision Making", International Journal of Production Research 35.11 (1997):2963-88. 8 August. 2014. 